\title{
The Effect of Pre-fermentative Freezing Treatment on the Sensory Quality of 'Meili' Rosé Wine
}

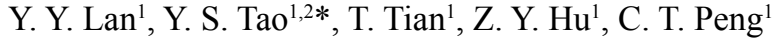 \\ (1) College of Enology, Northwest A\&F University, Yangling, Shaanxi 712100, China \\ (2) Shaanxi Engineering Research Centre for Viti-Viniculture, 22 Xinong Road, Yangling, Shaanxi 712100, China
}

Submitted for publication: March 2014

Accepted for publication: April 2014

Key words: Pre-fermentative freezing, 'Meili' wine, colour index, sensory attributes

\begin{abstract}
In this study, the effect of a pre-fermentative freezing treatment on quality attributes of 'Meili' rosé wine was assessed. Prior to fermentation, 'Meili' grapes (berries and must) were subjected to a freezing treatment considering factors of freezing temperatures, freezing time, and thawing method. Colour-related indices were measured by spectral methods. Wine aroma characteristics and sensory attributes were assessed by trained panellists. The results revealed that lower freezing temperature and longer freezing time had positive effects on wine quality attributes. The treatment of frozen berries might help extract colourrelated compounds. Microwave thawing improved wine colour, but decreased taste quality. In the work, the $\mathrm{MF}-10^{\circ} \mathrm{C} / 6 \mathrm{~h}$ treatment (microwave-thawed berries that had been frozen at $-10^{\circ} \mathrm{C}$ for $6 \mathrm{~h}$ ) contributed to the best colour characteristics, whereas the $\mathrm{NP}-20^{\circ} \mathrm{C} / 4 \mathrm{~h}$ treatment (naturally-thawed must that had been frozen at $-20^{\circ} \mathrm{C}$ for $4 \mathrm{~h}$ ) contributed to the best taste attributes.
\end{abstract}

\section{INTRODUCTION}

The quality attributes of wine include colour, aroma and taste. The quality attributes of red wine are attributed mostly to the presence of phenolic compounds in the berry skin. Their presence in the wine depends on several factors, including grape cultivar, maturity, soil, climate and production method (Auw et al., 1996). To extract phenolic compounds, different vinification treatments are used to rupture the cell walls of the berry skin. In recent years, several studies have focused on the effects of different vinification treatments on the quality attributes of wine. However, few studies have focused on the effects of freezing extraction on wine quality. One vinification treatment includes a pre-fermentative freezing treatment, which is performed at temperatures lower than $-8^{\circ} \mathrm{C}$, i.e. the ice-temperature point of grapes. During freezing extraction, ice crystals rupture the berry skin cell walls, thereby promoting the release of anthocyanins, tannins and aroma precursors (Couasnon, 1999; Parenti et al., 2004). Couasnon (1999), who assessed the effects of pre-fermentative maceration on Merlot wine, reported that dry ice-treated wine had a higher content of total polyphenols and anthocyanins than control wine. The positive effects of cold pre-fermentative maceration on phenolic extraction and wine colour have been reported in several wine varieties, including Monastrell (Álvarez et al., 2006), Syrah (GómezMíguez et al., 2007), Cabernet Sauvignon (Gil-Muñoz et al., 2009) and Tempranillo (Puertas et al., 2008; Gordillo et al., 2010). In contrast, Pérez-Lamela et al. (2007) and
Soto-Vázquez et al. (2010) reported insignificant colour improvements in Sousón, Brancellao and Mencía wines following pre-fermentative cold maceration.

In this study, the pre-fermentative freezing treatment was applied to 'Meili' grapes, a novel rosé grape cultivar released by Northwest A\&F University in China in 2010. The cultivar has been bred with European cultivars of grapevine (Vitis vinifera L.), including Merlot, Riesling and Muscat. Contrary to its parent lines, this variety is highly diseaseand cold-resistant. However, 'Meili' is difficult to ripen sufficiently for wine production in Shaanxi province, since a lot of rain falls in its maturation period. In winemaking, sugar is added to adjust the alcohol degree. Therefore, to enhance wine quality and explore this novel grape cultivar, pre-fermentative freezing treatment was used in this study to make rosé wine from 'Meili' grapes. We have published a previous study on the influence of pre-fermentative freezing treatment on wine aroma (Peng et al., 2013). The effects of pre-fermentative freezing treatment on overall wine quality are evaluated in this study.

\section{MATERIALS AND METHODS \\ Grapes}

'Meili' was grown in an experimental vineyard called Caoxin Zhuang, which is located in Yangling, Shaanxi, China. Because of the great deal of rain in the maturity period, grapes were picked manually in July 2010 to avoid the warm, damp late summer, which favours fungal diseases. About $650 \mathrm{~kg}$

*Corresponding author: taoyongsheng@nwsuaf.edu.cn [Tel.: +86-29-87092233,Fax: +86-29-87091133]

Acknowledgements: The authors are grateful for financial support under the National Natural Science Foundation of China (Grant No. 31371724) and the China Key Technology R\&D Program (Grant No. 2012BAD31B07) 
of grapes were collected. The juice had a titratable acidity of $8.5 \mathrm{~g} / \mathrm{L}$ (expressed as tartaric acid) and reducing sugars of $160 \mathrm{~g} / \mathrm{L}$.

\section{Vinification treatment}

The winemaking process was similar to that described by Peng et al., 2013. Because 'Meili' is a rosé grape, a modified red wine-making process was used to extract enough pigment into the rosé wine. The primary vinification of the control wine was carried out in the following manner. Grapes were destemmed and crushed in a pocket grape destemmer-crusher. The must was treated with sulphur dioxide (about $50 \mathrm{mg} / \mathrm{L})$ in stainless steel tanks $(50 \mathrm{~L}$ capacity) to settle for approximately $24 \mathrm{~h}$. Active dry yeast powder (Laffort Company, France) was used to start must fermentation. Fermentation was carried out at 25 to $30^{\circ} \mathrm{C}$. Sugar was added to increase the alcohol content to $11 \%$ (vol) during the vigorous fermentation period. When the specific gravity decreased to 1.020 (the residual sugar was about $35 \mathrm{~g} / \mathrm{L}$ ), the pomace was separated from the wines. The wine was then fermented at 18 to $20^{\circ} \mathrm{C}$ until dry (residual sugar less than $2 \mathrm{~g} / \mathrm{L}$ ). The entire fermentation lasted eight to nine days. After fermentation, the wine was racked, and sulphur dioxide (about $50 \mathrm{mg} / \mathrm{L}$ ) was added. The wine was the stabilised using the general stabilising processes, which included fining with $1.0 \mathrm{~g} / \mathrm{L}$ bentonite, cold treatment at $-4^{\circ} \mathrm{C}$ for 8 days, and enclosed racking. The wine was stored at $4^{\circ} \mathrm{C}$ in stainless steel tanks until May of the following year, after which it was bottled to be analysed. For the pre-fermentative freezing processes, grapes or the must was frozen after crushing. Berries were thawed to room temperature and then were destemmed and crushed. The following processes were the same as in the vinification treatment of the control. If the must was frozen, it was inoculated with yeast after being thawed to room temperature. Then the following processes were the same.

The pre-fermentative freezing process was designed taking the following four influencing factors into consideration: freezing temperature $\left(-20\right.$ and $\left.-10^{\circ} \mathrm{C}\right)$, freezing time (4 and $6 \mathrm{~h}$ ), grape state during freezing (must $(\mathrm{P})$ and berry $(\mathrm{F})$ ), and thawing methods (microwave thawing (M) and natural thawing (N)). Each treatment was done in duplicate.

\section{Apparatus and reagents}

AUV-2450 spectrophotometer was purchased from Shimadzu (Daojin, Beijing section, China). Water was filtered through a Milli-Q filtration system (Millipore, Molsheim, France). A "Le Nez du Vin" aroma kit was purchased from Yixiangle Company (54 aromas, Hong Kong). Commercial yeast X16 for alcohol fermentation was purchased from Laffort Company (France). All chemicals were of analytical reagent grade. Sulphite solution (6\%), hydrochloric acid (37\%), absolute ethanol and acetaldehyde were purchased from Xi'an chemical factory (Xi'an, China). Gallic acid (97\%), quercetin and caffeic acid (98\%) were obtained from SigmaAldrich (St. Louis, MO, USA). Malvidin-3-glucoside was supplied by Extrasythèse (Lyon, France).

\section{Determination of colour-related indices}

The procedure was based on that described by Cliff et al. (2007). Wine samples $(0.5 \mathrm{ml})$ were diluted to $5 \mathrm{ml}$ with $10 \%$ ethanol. A $0.25 \mathrm{ml}$ aliquot of each diluted sample was mixed with $0.25 \mathrm{ml}$ of $0.1 \% \mathrm{HCl}$ in $95 \%$ ethanol and $4.55 \mathrm{ml}$ of $2 \% \mathrm{HCl}$. Each sample was mixed in a vortex and allowed to stand for $15 \mathrm{~min}$. Absorbance was measured in $1 \mathrm{~cm}$ quartz cuvettes at 280, 320, 360 and $520 \mathrm{~nm}$. Absorbance readings at each wavelength corresponded to total phenolic $\left(\mathrm{A}_{280}\right)$, tartaric ester $\left(\mathrm{A}_{320}\right)$, flavonol $\left(\mathrm{A}_{360}\right)$ and anthocyanin $\left(\mathrm{A}_{520}\right)$ contents, which were determined from standard curves generated with standards of gallic acid (in 10\% ethanol), quercetin (in 95\% ethanol), caffeic acid (in 10\% ethanol), and malvidin-3-glucoside (in 10\% ethanol) at 280, 320, 360 and $520 \mathrm{~nm}$ respectively.

Co-pigmented, monomeric, polymeric and total anthocyanin contents in each wine were determined based on the colorimetric effects that $\mathrm{SO}_{2}$ and acetaldehyde have on different anthocyanins. In this experiment, $20 \mu \mathrm{l}$ of $20 \%$ acetaldehyde was mixed with $2 \mathrm{ml}$ of wine sample, which was allowed to stand for approximately $45 \mathrm{~min}$. To another $2 \mathrm{ml}$ wine sample, $160 \mu \mathrm{l}$ of $6 \%$ (w/v) $\mathrm{SO}_{2}$ was added. The absorbance of each sample was measured at $520 \mathrm{~nm}$ in $1 \mathrm{~mm}$ quartz cuvettes. Absorbance was also measured at $520 \mathrm{~nm}$ in samples without acetaldehyde or $\mathrm{SO}_{2}$. Co-pigmented anthocyanins $=\left(A^{\text {ace }}-A^{\text {wine }}\right)$, monomeric anthocyanins $=$ $\left(A^{\text {wine }}-A^{\mathrm{SO} 2}\right)$, polymeric anthocyanins $=\left(A^{\mathrm{SO} 2}\right)$, and total anthocyanins $=\left(A^{\text {ace }}\right)$.

The spectral absorbance of the wine samples at 420, 520 and $700 \mathrm{~nm}$ was determined in $1 \mathrm{~mm}$ cuvettes. Colour density and colour hue were calculated by the following equations:

Colour density $=\left[\left(A_{520}-A_{700}\right)+\left(A_{420}-A_{700}\right)\right]$ Colour hue $=\left[\left(A_{420}-A_{700}\right) /\left(A_{520}-A_{700}\right)\right]$.

\section{CIELAb parameters}

Wine samples were filtered through a $0.45 \mu \mathrm{m}$ membrane. Distilled water was used as a control. All samples were scanned by spectral absorbance from 190 to $1100 \mathrm{~nm}$, with a scanning interval of $1 \mathrm{~nm}$, and $1600 \mathrm{~ms}$ sampling using $2 \mathrm{~mm}$ quartz cuvettes. The absorbance readings at 450,520 , 570 and $630 \mathrm{~nm}$ were used to calculate $\mathrm{L}, \mathrm{a}^{*}, \mathrm{~b}^{*}$, metric chroma (C) and hue angle $(h)$ values using an original software CromaLab ${ }^{c}$ (Tao \& Zhang, 2010).

\section{Total tannin content}

A wine sample of $2 \mathrm{ml}$ was diluted 50 times to $100 \mathrm{ml}$ with distilled water. Aliquots of $2 \mathrm{ml}$ of each diluted wine sample were added to two tubes containing $1 \mathrm{ml}$ distilled water and $6 \mathrm{ml}$ concentrated hydrochloric acid. One tube was sealed with a plug, wrapped in aluminium foil (i.e. processed in the dark), placed in a boiling water bath for $30 \mathrm{~min}$, and cooled rapidly. The second tube was sealed with a plug, processed in the dark with silver paper, and placed in a warm temperature water bath for $30 \mathrm{~min}$. To each tube, $1 \mathrm{ml}$ of absolute ethanol was added. The absorbance of each solution was measured at $550 \mathrm{~nm}$. The total tannin content was calculated by the following equation: 
Total tannin $=\left(\mathrm{A}_{1}-\mathrm{A}_{2}\right) \times 19.33 \mathrm{~g} / \mathrm{L}$,

where $A_{1}$ and $A_{2}$ correspond to the absorbance readings obtained from the two tubes. The term 19.33 was a molar extinction coefficient of cianidine obtained by the acid hydrolysis of condensed tannins (Ribéreau-Gayon \& Stonestreet, 1966).

\section{Ethanol index}

The ethanol index is indicative of the amount of condensed tannin polysaccharides precipitated by the addition of ethanol. In this experiment, $9 \mu 1$ of ethanol was mixed with $1 \mu \mathrm{l}$ of wine sample, which was subsequently allowed to stand for $24 \mathrm{~h}$ and centrifuged. The resulting supernatant was diluted 100 times its original volume. Absorbance was measured at $280 \mathrm{~nm}\left(\mathrm{~A}_{2}\right)$ in $1 \mathrm{~cm}$ cuvettes. Subsequently, $1 \mu \mathrm{l}$ of wine sample was diluted 100 times and absorbance was measured at $280 \mathrm{~nm}\left(\mathrm{~A}_{1}\right)$.

Ethanol index $=100 \times(A 1-A 2) / A 1$

\section{HCl index}

Procyanidins are unstable in highly acidic environments. The $\mathrm{HCl}$ index, which ranges from 5 to 40 , represents the degree of polymerisation of wine tannins. Low values indicate light wines, medium values indicate balanced wines, and high values indicate wines with highly polymerised phenols.

In this experiment, $1 \mu \mathrm{l}$ of water and $3 \mu \mathrm{l}$ of $12 \mathrm{~N} \mathrm{HCl}$ were added to $2 \mathrm{ml}$ of wine sample. The solution was diluted 30 times its original volume. Absorbance was measured immediately in $1 \mathrm{~cm}$ cuvettes at $280 \mathrm{~nm}\left(\mathrm{~A}_{1}\right)$. Absorbance of another sample that was allowed to stand for $7 \mathrm{~h}$ in $\mathrm{HCl}$ prior to dilution and centrifugation was similarly measured at 280 $\mathrm{nm}\left(\mathrm{A}_{2}\right)$. The $\mathrm{HCl}$ index was calculated using the following equation:

$\mathrm{HCl}$ index $=100 \times(A 2-A 1) / A 1$

\section{Sensory analysis}

Sensory analysis was performed by a trained tasting panel. The panel of tasters, consisting of 30 students (12 men, 18 women, aged 22 to 24 years), had been trained with a standard aroma kit and taste solutions for two months. Solutions containing different concentrations of table sugar ( 0 to $12 \mathrm{~g} / \mathrm{L}$ ) for sweetness, ethanol (0 to $15 \% \mathrm{vol}$ ) for alcohol, tartaric acid ( 0 to $1.5 \mathrm{~g} / \mathrm{L})$ for acidity, quinine sulphate $(0$ to $10 \mathrm{mg} / \mathrm{L}$ ) for bitterness, and potassium and aluminium sulphate $(0$ to $5 \mathrm{~g} / \mathrm{L})$ for astringency stimuli were presented to the panel to aid with the recognition of and discrimination between the different oral sensations. When the identification accuracy of each item for the panel was more than $95 \%$, the sensory analysis could be carried out. Sensory analysis was performed in the sensory analysis laboratory. Each panellist had an independent space and tasted the wine individually. Each test session consisted of two blocks, with each block containing four randomised wine samples labelled with three-digit codes. Wine samples were prepared at $20^{\circ} \mathrm{C}$ $(20 \mathrm{ml})$. Tasters were separated in individual tasting cubicles with controlled lighting and temperature $\left(20^{\circ} \mathrm{C}\right)$. Each taster smelled the wines for 5 to $8 \mathrm{~s}$ in still stage and then smelled the wines for 5 to $10 \mathrm{~s}$ while swirling the glass. The average time interval between each sample was 1 to $2 \mathrm{~min}$. Tasters were given instructions to sip the wine, allowing it to cover the tongue surface, and to sip air, allowing it to mix with the wine for 5 to $6 \mathrm{~s}$. Finally, the tasters were instructed to spit the wine and perceive the aftertaste for 3 to $4 \mathrm{~s}$. Each wine sample was tested three times. The tasters scored the intensity of each wine quality attribute (i.e. appearance, aroma and taste) using a 5-point scale: 1 - very weak, 2 weak, 3 - medium, 4 - intense, 5 - very intense. The data, which consisted of a combination of intensity and frequency of detection ("modified frequency", $M F$ ), was calculated with the formula

$$
M F \%=\sqrt{F(\%) I(\%)}
$$

where $F(\%)$ is the detection frequency of a sensory attribute and $I(\%)$ is the average intensity expressed as a percentage of the maximum intensity.

\section{Statistical analyses}

Analysis of variance (ANOVA) and principal component analysis (PCA) were performed to assess the effects of different freezing extraction conditions on wine quality attributes. SPSS 19.0 for Windows (SPSS Inc., Chicago, IL, USA) was used.

\section{RESULTS AND DISCUSSION \\ Colour-related indices}

The colour-related indices of the wine samples are shown in Table 1. Compared with the control wines, the treated wines had more monomeric anthocyanins and total tannins. The different treatments had no consistent effects on wine colour-related indices, except on co-pigmented anthocyanins and total tannins.

The PCA result is shown in Fig. 1, which reveals the colour-related indices and sample wine distribution in the first two PCs: PC1 (59.6\%) and PC2 (15.6\%). Anthocyanins, tartaric ester, total phenolics, total anthocyanins, flavonols, polymeric anthocyanins and colour density made more positive contributions to $\mathrm{PC} 1$, while $\mathrm{L}, \mathrm{b}^{*}, \mathrm{a}^{*}$ and colour hue made negative contributions to PC1. Accordingly, $\mathrm{PC} 1$ can be considered as a colour density component. PC 2 effectively separated the control wine from the treated wines; all treated wine samples were located above the control. Compared with the treated wines, the control wine was in the negative quadrant of PC2 and was approximately zero in PC1.

The treatments of frozen berries had significant effects on the extraction of colour-related compounds. As shown in Fig. 1, all treatments of frozen berries were in the right quadrant of PC1 and most treatments of frozen musts were in the left quadrant. This discrepancy was attributed to the colour density of the wines. Consequently, freezing was beneficial for the extraction of colour-related compounds. In terms of temperature, there were no significant differences between the two freezing temperatures. Álvarez et al. (2006) reported that extended maceration time improve polyphenolic content; however, this result was not obtained in our study. As a result, freezing temperatures and freezing time may affect wine colour in different ways while interacting with other factors.

Microwave thawing methods, especially microwave- 
TABLE 1

The colour-related indices of the sample wines.

\begin{tabular}{|c|c|c|c|c|c|c|c|c|c|c|c|c|}
\hline \multirow{3}{*}{ Items } & \multirow{3}{*}{$\mathrm{CK}^{\mathrm{a}}$} & \multicolumn{4}{|c|}{ Berry } & \multicolumn{6}{|c|}{ Must } & \multirow{3}{*}{ Sig. } \\
\hline & & \multicolumn{2}{|c|}{$\mathrm{M}^{\mathrm{b}}$} & \multirow{2}{*}{$\frac{\mathrm{N}^{\mathrm{b}}}{-20^{\circ} \mathrm{C} / 4 \mathrm{~h}}$} & \multirow{2}{*}{ Sig. } & \multicolumn{2}{|c|}{ M } & \multicolumn{3}{|c|}{$\mathrm{N}$} & \multirow{2}{*}{ Sig. } & \\
\hline & & $-20^{\circ} \mathrm{C} / 4 \mathrm{~h}$ & $-10^{\circ} \mathrm{C} / 6 \mathrm{~h}$ & & & $-10^{\circ} \mathrm{C} / 6 \mathrm{~h}$ & $-10^{\circ} \mathrm{C} / 4 \mathrm{~h}$ & $-20^{\circ} \mathrm{C} / 4 \mathrm{~h}$ & $-10^{\circ} \mathrm{C} / 6 \mathrm{~h}$ & $-10^{\circ} \mathrm{C} / 4 \mathrm{~h}$ & & \\
\hline $\begin{array}{l}\text { Monomeric } \\
\text { anthocyanins }\end{array}$ & 0.27 & 0.99 & 0.52 & 0.35 & ns & 0.73 & 0.58 & 1.7 & 0.52 & 0.4 & $n s^{b}$ & $\mathrm{~ns}$ \\
\hline $\begin{array}{l}\text { Polymeric } \\
\text { anthocyanins }\end{array}$ & 0.51 & 2.67 & 0.33 & 0.37 & ns & 0.33 & 0.4 & 0.81 & 0.92 & 0.31 & ns & ns \\
\hline $\begin{array}{l}\text { Co-pigmented } \\
\text { anthocyanins }\end{array}$ & 9.85 & 4.34 & 1.81 & 2.19 & $\mathrm{~ns}$ & 1.74 & 3.32 & 2.7 & 4.53 & 2.04 & ns & $* * \mathrm{~b}$ \\
\hline $\begin{array}{l}\text { Total } \\
\text { anthocyanins }\end{array}$ & 2.56 & 3.34 & 1.63 & 1.85 & $\mathrm{~ns}$ & 1.64 & 2.01 & 4.03 & 4.59 & 1.53 & ns & ns \\
\hline Colour density & 0.84 & 1.24 & 0.55 & 0.66 & ns & 0.68 & 0.55 & 1.38 & 1.35 & 0.57 & ns & ns \\
\hline Hue & 3.99 & 2.34 & 8.41 & 1.09 & ns & 4.38 & 6.58 & 2.16 & 2.17 & 1.01 & $* \mathrm{~b}$ & ns \\
\hline $\mathrm{HCl}$ index & 8 & 23.12 & 10.78 & 9.57 & ns & 31.71 & 17.84 & 45.33 & 3.35 & 5.38 & ns & ns \\
\hline Ethanol index & 92.19 & 80.91 & 71.91 & 80.48 & ns & 85.32 & 82.18 & 82.01 & 91.73 & 83.24 & ns & ns \\
\hline $\begin{array}{l}\text { Total tannins } \\
(\mathrm{g} / \mathrm{L})^{\mathrm{c}}\end{array}$ & 0.58 & 1.49 & 1.22 & 1.82 & $\mathrm{~ns}$ & 1.3 & 1.31 & 1.72 & 1.39 & 1.8 & ns & $*$ \\
\hline $\begin{array}{l}\text { Total phenolics } \\
(\mathrm{mg} / \mathrm{L})^{\mathrm{c}}\end{array}$ & 402.25 & 383.52 & 413.68 & 436.86 & ns & 485.75 & 447.97 & 396.54 & 424.48 & 443.52 & ns & ns \\
\hline $\begin{array}{l}\text { Tartaric esters } \\
(\mathrm{mg} / \mathrm{L})^{\mathrm{c}}\end{array}$ & 42.59 & 41.23 & 44.25 & 45.49 & $\mathrm{~ns}$ & 51.72 & 46.4 & 41.14 & 42.92 & 46.46 & $\mathrm{~ns}$ & ns \\
\hline $\begin{array}{l}\text { Flavonols } \\
(\mathrm{mg} / \mathrm{L})^{\mathrm{c}}\end{array}$ & 25.97 & 25.95 & 26.28 & 26.76 & ns & 28.12 & 27.02 & 26.09 & 26.38 & 27.05 & ns & ns \\
\hline $\begin{array}{l}\text { Anthocyanins } \\
(\mathrm{mg} / \mathrm{L})^{\mathrm{c}}\end{array}$ & 99.39 & 100.11 & 95.82 & 100.46 & ns & 115.46 & 104.39 & 101.18 & 104.75 & 102.25 & ns & ns \\
\hline $\mathrm{L}$ & 66.9 & 38.2 & 35.2 & 70.6 & $*$ & 98.5 & 78.6 & 46.9 & 35.2 & 87.5 & ns & ns \\
\hline $\mathrm{C}$ & 68.02 & 39.31 & 39.91 & 72.13 & $* *$ & 114.5 & 77.68 & 57.44 & 39.91 & 90.77 & ns & ns \\
\hline $\mathrm{h}$ & 91.99 & 79.51 & 68.82 & 106.8 & ns & 128.2 & 107.6 & 66.64 & 68.82 & 118.9 & ns & ns \\
\hline$a^{*}$ & -2.37 & 7.16 & 14.42 & -20.85 & $\mathrm{~ns}$ & -70.79 & -23.48 & 22.78 & 14.42 & -43.87 & $\mathrm{~ns}$ & $\mathrm{~ns}$ \\
\hline$b^{*}$ & 67.98 & 38.65 & 37.21 & 69.05 & $*$ & 89.99 & 74.05 & 52.73 & 37.21 & 79.47 & ns & $\mathrm{ns}$ \\
\hline
\end{tabular}

${ }^{\mathrm{a}} \mathrm{CK}$, Control wines; ${ }^{\mathrm{b}} \mathrm{M}$, microwave thawing; N, natural thawing; ns: not significant; $* \mathrm{p}<0.05 ; * * \mathrm{p}<0.01$; ${ }^{\mathrm{c}}$ Total phenolics were determined as gallic acid (in 10\% ethanol); Tartaric esters were determined as quercetin (in 95\% ethanol); Flavonols were determined as caffeic acid (in 10\% ethanol); Anthocyanins were determined as malvidin-3-glucoside (in 10\% ethanol).

thawed berries (MF) frozen at $-10^{\circ} \mathrm{C}$ for $6 \mathrm{~h}\left(\mathrm{MF}-10^{\circ} \mathrm{C} / 6 \mathrm{~h}\right)$, had higher scores in PC1 than the control wine. Microwavethawed wine samples were located in the right quadrant of PC1. Álvarez et al. (2006) reported the same findings in Monastrell red wines. According to the authors, prefermentative cold maceration significantly increased colourrelated indices compared to the control wine. On the other hand, naturally thawed must samples, especially naturally thawed must (NP) $\mathrm{NP}-20^{\circ} \mathrm{C} / 4 \mathrm{~h}, \mathrm{NP}-10^{\circ} \mathrm{C} / 4 \mathrm{~h}$ and $\mathrm{NP}-$ $10^{\circ} \mathrm{C} / 6 \mathrm{~h}$, were in the left quadrant of $\mathrm{PC} 1$, indicating that these treatments seldom affect colour-related indices. No substantial improvements in colour-related indices of prefermentative macerated wines were reported by PérezLamela et al. (2007) and Soto-Vázquez et al. (2010). Therefore, microwave thawing treatments increased the extraction of anthocyanins and phenolic compounds, while natural thawing treatments had insignificant effects.

\section{Sensory attributes}

Our previous work evaluated the influence of the prefermentative freezing treatment on 'Meili' wine aroma. It was revealed that pre-fermentative freezing could enhance wine aroma intensity and complexity. Natural thawing treatment of frozen must with skins resulted in higher aroma quality. Lower freezing temperature contributed to higher esters and organic acids (Peng et al., 2013). The data on the overall sensory attributes in this work are shown in Table 2. The PCA of the sensory data explained $72.6 \%$ of the variation in the first two PCs: PC1 (42.8\%) and PC2 (29.8\%). Fig. 2 shows the loadings of all sensory attributes and wine sample distributions in the first two PCs. Most attributes were concentrated in the positive quadrant of PC1. Cherry colour, appearance, sour and feedback were located in the positive quadrant of PC2, while chemical smell, aroma intensity and violet colour were in the opposite quadrant. 


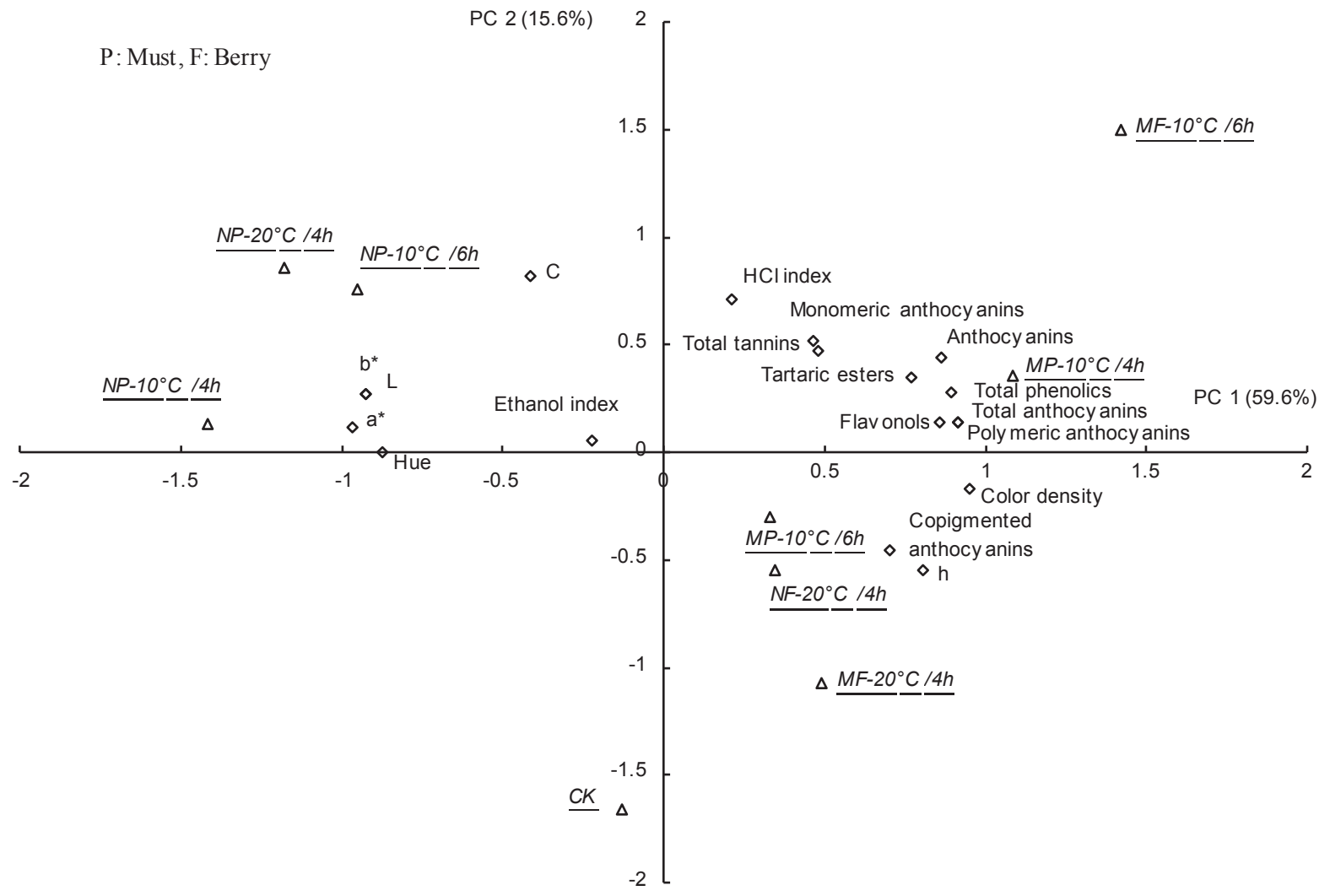

FIGURE 1

Loading scores of colour-related indices and the distribution of wines in the first two PCs

TABLE 2

$\mathrm{MF} \%$ of the sensory attributes of the sample wines.

\begin{tabular}{|c|c|c|c|c|c|c|c|c|c|c|}
\hline \multirow{3}{*}{ Attributes } & \multirow{3}{*}{$\mathrm{CK}^{\mathrm{a}}$} & \multicolumn{5}{|c|}{ Must } & \multicolumn{3}{|c|}{ Berry } & \multirow{3}{*}{ Sig } \\
\hline & & \multicolumn{2}{|c|}{$\mathrm{M}^{\mathrm{b}}$} & \multicolumn{3}{|c|}{$\mathrm{N}^{\mathrm{b}}$} & \multirow{2}{*}{$\frac{\mathrm{N}}{-20^{\circ} \mathrm{C} / 4 \mathrm{~h}}$} & \multicolumn{2}{|c|}{$\mathrm{M}$} & \\
\hline & & $-10^{\circ} \mathrm{C} / 6 \mathrm{~h}$ & $-10^{\circ} \mathrm{C} / 4 \mathrm{~h}$ & $-20^{\circ} \mathrm{C} / 4 \mathrm{~h}$ & $-10^{\circ} \mathrm{C} / 4 \mathrm{~h}$ & $-10^{\circ} \mathrm{C} / 6 \mathrm{~h}$ & & $-20^{\circ} \mathrm{C} / 4 \mathrm{~h}$ & $-10^{\circ} \mathrm{C} / 6 \mathrm{~h}$ & \\
\hline Appearance & 72.0 & 67.0 & 72.0 & 75.0 & 68.0 & 68.0 & 62.0 & 76.0 & 74.0 & $n \mathrm{~s}^{\mathrm{b}}$ \\
\hline Colour depth & 68.0 & 64.0 & 76.0 & 74.0 & 79.0 & 80.0 & 65.0 & 77.0 & 73.0 & ns \\
\hline Cherry colour & 71.0 & 62.0 & 68.0 & 80.0 & 57.0 & 57.0 & 58.0 & 72.0 & 67.0 & ns \\
\hline Violet colour & 44.0 & 42.0 & 41.0 & 44.0 & 75.0 & 75.0 & 31.0 & 50.0 & 39.0 & ns \\
\hline Aroma intensity & 75.0 & 77.0 & 72.0 & 77.0 & 78.0 & 83.0 & 78.0 & 78.0 & 72.0 & ns \\
\hline Aroma permanence & 53.0 & 58.0 & 59.0 & 64.0 & 57.0 & 58.0 & 60.0 & 63.0 & 58.0 & ns \\
\hline Flavour & 54.0 & 58.0 & 54.0 & 63.0 & 60.0 & 55.0 & 58.0 & 63.0 & 59.0 & ns \\
\hline Mellow & 62.0 & 60.0 & 62.0 & 62.0 & 64.0 & 64.0 & 62.0 & 61.0 & 62.0 & ns \\
\hline Sour & 67.0 & 81.0 & 74.0 & 80.0 & 72.0 & 70.0 & 74.0 & 81.0 & 78.0 & ns \\
\hline Depth & 68.0 & 70.0 & 70.0 & 75.0 & 68.0 & 71.0 & 70.0 & 74.0 & 67.0 & ns \\
\hline Body & 63.0 & 70.0 & 66.0 & 71.0 & 66.0 & 67.0 & 69.0 & 70.0 & 67.0 & ns \\
\hline Tannin & 55.0 & 57.0 & 57.0 & 63.0 & 64.0 & 68.0 & 63.0 & 63.0 & 59.0 & ns \\
\hline Astringency & 53.0 & 49.0 & 54.0 & 62.0 & 60.0 & 63.0 & 64.0 & 63.0 & 56.0 & ns \\
\hline Bitterness & 55.0 & 59.0 & 56.0 & 62.0 & 61.0 & 67.0 & 63.0 & 60.0 & 57.0 & ns \\
\hline Chemical & 28.0 & 38.0 & 34.0 & 40.0 & 50.0 & 46.0 & 43.0 & 38.0 & 37.0 & ns \\
\hline Alcoholic & 53.0 & 59.0 & 51.0 & 62.0 & 62.0 & 60.0 & 60.0 & 63.0 & 58.0 & ns \\
\hline Feedback & 54.0 & 55.0 & 54.0 & 58.0 & 54.0 & 53.0 & 55.0 & 59.0 & 57.0 & ns \\
\hline Re-fruity ${ }^{c}$ & 55.0 & 57.0 & 54.0 & 64.0 & 62.0 & 60.0 & 61.0 & 59.0 & 54.0 & ns \\
\hline
\end{tabular}

${ }^{\mathrm{a}} \mathrm{CK}$, Control wines; ${ }^{\mathrm{b}} \mathrm{M}$, microwave thawing; N, natural thawing; ns: not significant; $* \mathrm{p}<0.05 ; * * \mathrm{p}<0.01 ;{ }^{\mathrm{c}}$ Re-fruity - the perceived fruitiness after spitting the wine. 


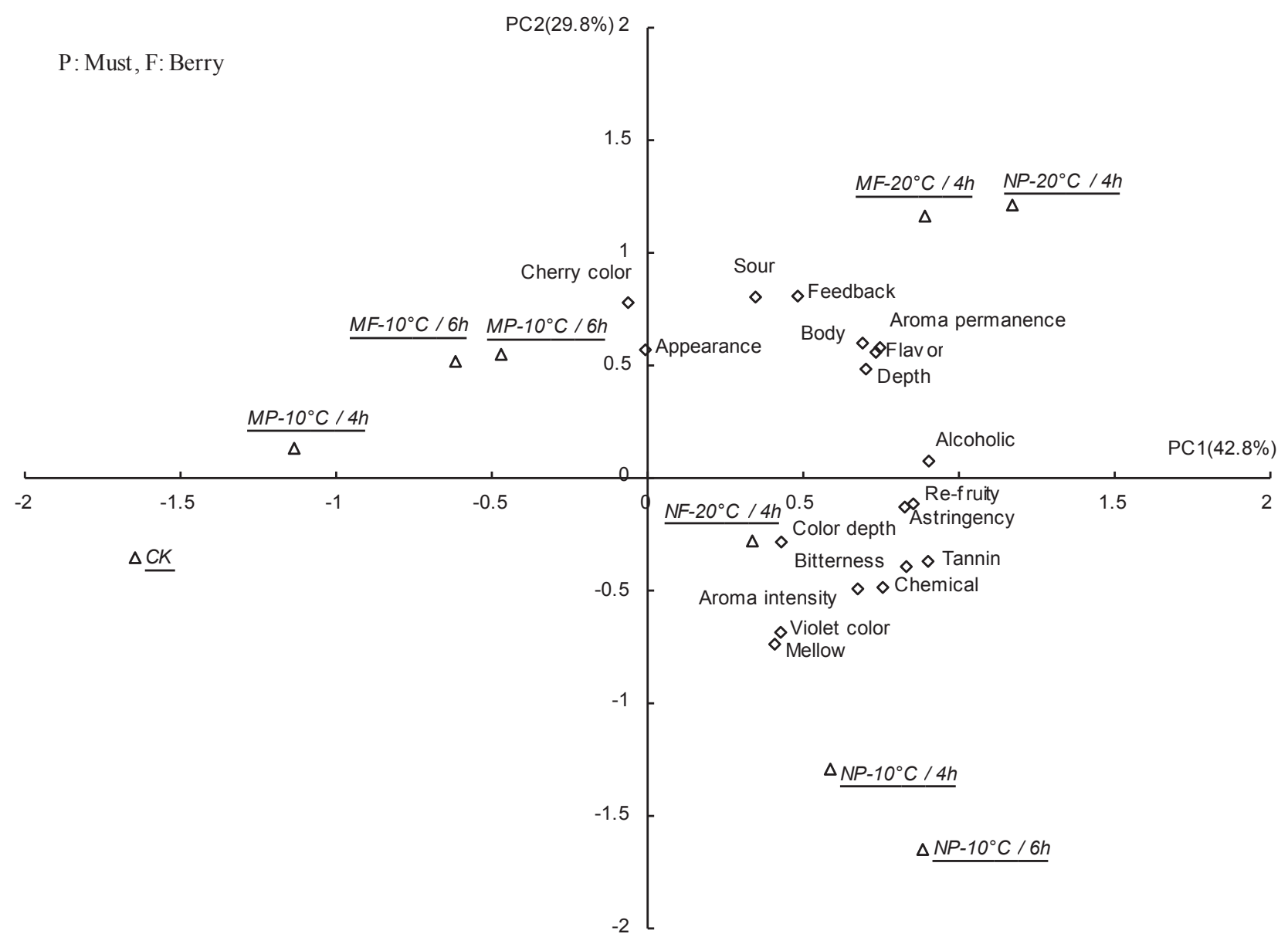

FIGURE 2

Loadings of sensory attributes and distribution of wines in the first two PCs

Heatherbell et al. (1997) reported that cold soaking reduces berry aromas and increases tobacco aroma and bitterness in Pinot noir. Cejudo-Bastante (2011) announced that pre-fermentative treatments improved wine quality based on higher tropical fruit, body and herbaceous notes. Similarly, according to the findings of Petrozziello et al. (2011), cryo-maceration increased floral and fruity notes. As shown in Fig. 2, all treated wines had higher scores on PC1 than the control wine, which indicated that pre-fermentative freezing treatment improved sensory quality. This finding was in accordance with the findings reported by Heatherbell et al. (1997), Cejudo-Bastante (2011), and Petrozziello et al. (2011). In addition, longer extraction time had positive effects on sensory attributes (e.g. MP $-10^{\circ} \mathrm{C} / 6 \mathrm{~h}$ versus MP$10^{\circ} \mathrm{C} / 4 \mathrm{~h}$ and $\mathrm{NP}-10^{\circ} \mathrm{C} / 6 \mathrm{~h}$ versus $\mathrm{NP}-10^{\circ} \mathrm{C} / 4 \mathrm{~h}$ ); however, this result was not in accordance with the findings of Álvarez et al. (2006). With the exception of NF- $20^{\circ} \mathrm{C} / 4 \mathrm{~h}$, treatments at $-20^{\circ} \mathrm{C}$ were in the positive quadrant of $\mathrm{PC} 1$ or $\mathrm{PC} 2$, whereas treatments at $-10^{\circ} \mathrm{C}$ were in the negative quadrant of $\mathrm{PC} 1$ or $\mathrm{PC} 2$. This result, which was in accordance with the findings of Parenti et al. (2004), suggested that lower freezing temperatures contributed to better appearance and taste and aroma, probably due to the accumulation of higher esters and organic acids (Peng et al., 2013). In this work, natural thawing treatments were more effective in enhancing sensory quality than microwave thawing treatments, since most of the microwave-thawed samples were in the negative quadrant of $\mathrm{PC} 1 . \mathrm{MF}-20^{\circ} \mathrm{C} / 4 \mathrm{~h}$ was an exception with its lower freezing temperature.

\section{CONCLUSIONS}

In this study, the effect of pre-fermentative freezing treatment on quality attributes of 'Meili' rosé wine was assessed. Different freezing conditions (i.e. freezing time, freezing temperature, thawing method and grape state) were evaluated. Extended freezing time had positive effects on wine quality attributes; however, its effect on colour was inconsistent. Lower freezing temperatures could improve quality attributes. Thawing methods had interesting effects on the treated wines. The microwave thawing method resulted in wines with better colour density. Grape state (i.e. berry versus must) affected quality attributes by interacting with other factors. The treatment of frozen berries may help extract colour-related compounds and phenolic composition. Based on the results, it was found that $\mathrm{MF}=10^{\circ} \mathrm{C} / 6 \mathrm{~h}$ contributed to the best colour, while $\mathrm{NP}-20^{\circ} \mathrm{C} / 4 \mathrm{~h}$ had the best sensory attributes.

\section{LITERATURE CITED}

Álvarez, I., Aleixandre, J.L., García, J. \& Lizama, V., 2006. Impact of pre-fermentative maceration on the phenolic and volatile compounds in Monastrell red wines. Anal. Chim. Acta, 563,109-115. 
Auw, J.M., Blanco, V., O'Keefe, S.F. \& Sims, C.A., 1996. Effect of processing on the phenolics and color of Cabernet Sauvignon: Chambourcin and Noble wines and juices. Am. J. Enol. Vitic. 47, 279-286.

Cejudo-Bastante, M.J., 2011. Combined effects of prefermentative skin maceration and oxygen addition of must on color-related phenolics, volatile composition, and sensory characteristics of Air. J. Agric. Food Chem. 59,12171-12182.

Cliff, M.A., King, M.C. \& Schlosser, J., 2007. Anthocyanin, phenolic composition, color measurement and sensory analysis of $\mathrm{BC}$ commercial red wines. Food Res. Int. 40, 92-100.

Couasnon, M., 1999. Une nuvelle technique: la maceration pre-fermentaire a froid-Extraction a la nieve carbonique, part I. Revue des oenologues et des techniques vitivinicoles et oenologiques 92, 26-30.

Gil-Muñoz, R., Moreno-Pérez, A., Vila-López, R., Fernández-Fernández, J.I., Martínez-Cutillas, A. \& Gómez-Plaza, E., 2009. Influence of low temperature pre-fermentative techniques on chromatic and phenolic characteristics of Syrah and Cabernet Sauvignon wines. Eur. Food Res. Technol., 228, 777-788.

Gómez-Míguez, M., González-Miret, M.L. \& Heredia, F.J., 2007. Evolution of color and anthocyanin composition of Syrah wines elaborated with prefermentative cold maceration. J. Food Eng., 79, 271-278.

Gordillo, B., López-Infante, M.I., Ramirez-Pérez, P., González-Miret, M.L. \& Heredia, F.J., 2010. Influence of prefermentative cold maceration on the color and anthocyanic copigmentation of organic Tempranillo wines elaborated in a warm climate. J. Agric. Food Chem., 58, 6797-6803.

Heatherbell, D., Dicey, M., Goldsworthy, S. \& Vanhanen, L., 1997. Effect of prefermentation cold maceration on the composition, color and flavor of Pinot Noir wine. In: T. Henick-Kling et al. (eds), Proc. 4th Int. Symp. Cool Climate Enology and Viticulture Communication Services, N.Y. State Agric. Exp. Sta., Geneva. pp. VI-10 - 17.
Parenti, A., Spugnoli, P., Calamai, L., Ferrari, S. \& Gori, C., 2004. Effects of cold maceration on red wine quality from Tuscan Sangiovese grape. Eur. Food Res. Technol. 218, 360-366.

Peng, C.T., Wen, Y., Tao, Y.S. \& Lan, Y.Y., 2013. Modulating the formation of Meili wine aroma by pre-fermentative freezing process. Agric. Food Chem. 61, 1542-1553.

Pérez-Lamela, C., García-Falcón, M.S., Simal-Gándara, J. \& OrriolsFernández, I., 2007. Influence of grape variety, vine system and enological treatments on the color stability of young red wines. Food Chem. 101, 601606.

Petrozziello, M., Guaita, M., Motta, S., Panero, L. \& Bosso, A., 2011. Analytical and sensory characterization of the aroma of "Langhe D.O.C. Nebbiolo" wines: Influence of the prefermentative cold maceration with dry ice. J. Food Sci. 76(4), 525-534.

Puertas, B., Guerrero, R.F., Jurado, M.S., Jiménez, M.J. \& Cantos-Villar, E., 2008. Evaluation of alternative winemaking processes for red wine color enhancement. Food Sci. Technol. Int. 15, 021-027.

Ribéreau-Gayon, P. \& Stonestreet, E., 1966. Dosage des tannins dans le vin rouge et détermenation de leur structure. Chim. Anal. 48, 188-196.

Soto-Vázquez, E., Río-Segade, S. \& Orriols-Fernández, I., 2010. Effect of wine-making technique on phenolic composition and chromatic characteristics in young red wines. Eur. Food Res. Technol. 231, 789-802.

Tao, Y.S. \& Zhang, L., 2010. Correlation analysis of CIELab parameters and anthocyanidins of different red wines (China). Sci. Agric. Sin. 43(20), 4271-4277. 